\title{
The ONS Longitudinal Study - a prestigious past and a bright future
}

Shayla Goldring and Jim Newman

Office for National Statistics

This issue of Population Trends includes a number of articles and reports resulting from research based on the ONS Longitudinal Study (ONS LS). They have been drawn together in one issue to highlight the value of this type of study for demographic research.

2009 marked the 35th anniversary of the establishment of the ONS LS. The study now contains data from the last four censuses (1971 to 2001), linked to vital events data since 1971, for a sample of one per cent of the population of England and Wales.

More recently, sister studies have been established in Scotland and Northern Ireland. The Scottish Longitudinal Study (SLS) started with 1991 Census data and the Northern Ireland Longitudinal Study (NILS) started with 2001 Census data.

The lead article in this issue comes from an exemplar project that was established to explore how to utilise the three studies to carry out UK-wide longitudinal analysis. Two different methods were used to analyse socio-economic and country level differences in health and mortality across the studies. The article summarises the results of this analysis, reports on the relative strengths of the different methods used, and draws attention to a number of new resources that have been developed by the project researchers as aids to using all three studies.

This is an excellent example of collaborative working across the UK, involving researchers from the Centre for Longitudinal Study Information and User Support (CeLSIUS) at the London School of Hygiene and Tropical Medicine, the Longitudinal Studies Centre Scotland (LSCS) at the University of St. Andrews and the Northern Ireland Longitudinal Study - Research Support Unit (NILS-RSU) at Queen's University Belfast. The project also involved collaboration between ONS, the General Register Office for Scotland (GROS) and the Northern Ireland Statistics and Research Agency (NISRA) to ensure the secure transfer and handling of data from the three studies so that it could be brought together in one place for analysis.

The other ONS LS-based articles and reports in this edition largely focus on research into issues related to families and households, as summarised below:

- A collaborative project involving Ben Wilson (ONS) and Rachel Stuchbury (CeLSIUS) comparing the stability of partnerships involving marriage and cohabitation.

- A project looking at transitions in children's experience of living in a workless household and how this varies by ethnic group, submitted by Lucinda Platt (Institute for Social \& Economic Research, University of Essex). 
- An article on the effect of a change in the census definition of a child between 1991 and 2001 submitted by Emily Grundy, Rachel Stuchbury and Harriet Young (CeLSIUS).

The remainder of this introductory article will focus on the ONS LS, its history and some examples of its use, and gives a summary of planned developments over the coming years. Please refer to the contact details at the end of the article if you require further information on any of the three longitudinal studies.

\section{Contents}

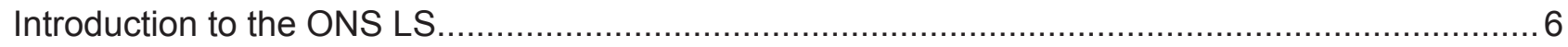

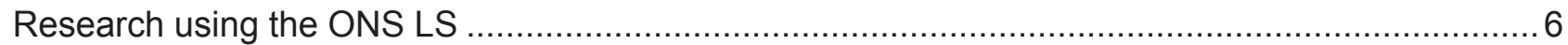

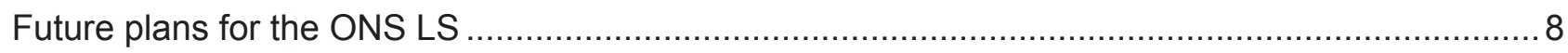

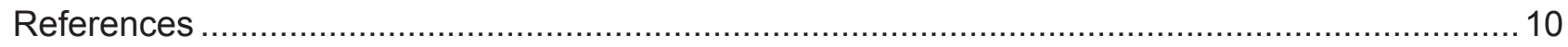




\section{Introduction to the ONS LS}

Longitudinal data sets are based on repeated measurements of a sample population. They allow us to answer questions about how a particular cohort of people changes over time, and to explore reasons for change. In addition, the ONS LS allows users to look at and compare the experiences of different cohorts at different points in time. This enables users to separate age, period and cohort effects in their analysis.

Cohort analysis was identified as a priority in developing the analysis of mortality by William Farr, a noted epidemiologist who was appointed the first 'Compiler of Abstracts' at the newly established General Register Office for England and Wales in 1839. At this time the analysis of information collected by statistical offices was mainly cross-sectional as a result of the limited data available. Farr was the first to combine information from a national census (1861) and the death registers to look at the occupation of men, their age at and cause of death.

The ONS LS was established in 1974 by taking a sample of records from the 1971 Census for England and Wales of all those born on one of four dates of birth. This original sample has been continuously augmented since 1971 with new members. New members enter the study through one of the following three routes if born on one of the four dates of birth:

- completion of a census form

- birth registration through the civil registration service; or

- registration as a patient with a doctor.

Information from the 1971, 1981, 1991 and 2001 Censuses has been linked, along with information on events such as births, deaths, immigration, emigration and cancer registrations for study members. More than half a million study members have been identified at each of the four censuses, and the study now includes information on more than one million different individuals.

The ONS LS is a study - not a survey. Its strength lies in the re-use of data that have already been collected for other purposes, significantly reducing the effects typically associated with respondent burden. As a result, both retention and response rates are relatively high.

\section{Research using the ONS LS}

The study was originally set up primarily to meet the need for better data on occupational mortality and fertility patterns.

Data at the time were inadequate for the study of occupational mortality rates. In order to provide evidence for a causal relationship between occupation and mortality, information on occupation is needed for a period well before the onset of illness and death. In addition, information on an individual's characteristics such as employment status, area of residence, qualifications and general health would be needed for some years before death to use as control variables, as these may also have an influence on mortality.

It was also accepted that there was a need for more detailed information on fertility patterns, in particular changes in the spacing of births, and the part that social and economic characteristics play in family formation.

The ONS LS addresses these needs, and many more, by linking existing census and vital event data. The strengths of the study include: 
- the robustness of the sample size, around 500,000 at any one census

- the relatively high rates of retention and response

- the range and stability of the information available for analysis over time, from censuses and vital events

- the inclusion of census information on co-residents of study members

- the availability of sister studies in Scotland and Northern Ireland for those interested in a UKwide perspective; and

- the services of dedicated user support teams (contact details for these teams are provided at the end of this article).

The ONS LS enables analysis of a wide range of key sub-groups and topics of policy interest. Since its inception, the study has been used to address research questions including studies of social mobility, ageing and migration. Studies that make the fullest use of the data link social, occupational and demographic information at successive censuses to data about fertility, mortality, and cancer incidence and survival. Some examples of recent research that used the ONS LS follow below.

In the field of fertility, the study has recently been used to explore lifelong childlessness ${ }^{1}$, a topic which has received little attention given the decline in fertility experienced since the baby boom. This research investigated the degree to which socio-economic characteristics of women and, where present, their partners were related to female lifelong childlessness. The study measured the extent to which women who remained childless throughout their life course were distinctive from those who became mothers, and therefore improved our understanding of childlessness among women in England and Wales.

The researchers on this project, Martina Portanti and Simon Whitworth from ONS, won the inaugural Neville Butler Memorial Prize in 2009, awarded by the Economic and Social Research Council for excellence in the analysis of longitudinal data. It received a great deal of media attention, as demonstrated by the following newspaper headlines:

"One in five women stays childless because of modern lifestyle", Daily Telegraph "Fifth of women childless as careers take precedence, study shows", The Times

Recent work in the field of mortality includes a project led by Dr David Pevalin from the School of Health and Human Sciences at Essex University. Dr Pevalin's research analysed social inequalities in avoidable mortality, looking to test empirically the theory of social conditions as fundamental causes of disease. Findings from this project were presented at the 2009 conference of the British Society for Population Studies.

The information available on co-residents from the census, and also vital events such as the registration of the death of a spouse, are very important for analyses of partnership formation and dissolution. This information means that it is possible to look at the characteristics of both partners in a relationship and use them or the differences between them to study the factors relating to the stability of different partnership types over time. This is the approach used by Ben Wilson and Rachel Stuchbury in their paper 'Do partnerships last? Comparing marriage and cohabitation using the ONS Longitudinal Study', included in this issue of Population Trends. 
The study also has internal uses within ONS, such as quality assurance of other data sources. It played a key role in the assessment and adjustment of population estimates based on the 2001 Census. Analysis using the study highlighted a shortfall in men aged 25 to 34 in the Census. The 2001 mid-year population estimates for 68 local authorities were adjusted as a result of this analysis. For more information on this analysis, refer to Section 7 of Series LS no. $10^{2}$ and the Census 2001 Quality Report for England and Wales ${ }^{3}$.

Planning for the 2011 Census reflects the importance of the part the study played after 2001 . This time the ONS LS will be a key source of data used in carrying out quality assurance of census data. This will allow information from the study to be considered alongside other quality assurance material before any population estimates are published.

\section{Future plans for the ONS LS}

\section{Linking data from the 2011 Census}

With the 2011 Census only a year away, plans for incorporating the next set of census data into the ONS LS are well advanced. As a result of this work, the study will contain linked data from five successive censuses. The new census data will be available from the study in autumn 2013.

The addition of 2011 Census data will enable users to study transitions in people's caring responsibilities for the first time. This isn't currently possible as the census question on caring was first asked in 2001. Many users will also want to update previous analyses such as

- socio-economic and/or ethnic differences in mortality, life expectancy, cancer incidence, fertility and migration behaviour; and

- transitions over time in topic areas such as occupational and social mobility, household composition and partnerships.

\section{UK-wide longitudinal study research}

As noted earlier, the establishment of longitudinal studies in Scotland and Northern Ireland means that a longitudinal study infrastructure now exists that enables researchers to take a UK-wide view, or to draw comparisons between different regions and countries across the whole of the UK.

While there are a number of differences in the structure, content and operation of the three studies, the basic principle behind each of them is essentially the same. That is, to link the wide range of information collected at each census with data from subsequent events, most notably those relating to fertility and mortality.

The exemplar project reported in this issue of Population Trends has involved both researchers and the statistical offices working through a number of issues that required resolution to allow this research to take place. These are reported on in a technical working paper on the CeLSIUS website.

One significant outcome of this work is that a provisional working model has been established for anyone wishing to conduct research across the three studies. As part of a wider review of user needs of the ONS LS, ONS will be gauging the demand for a more permanent solution that allows UK-wide research to take place. Further work on this will be led by ONS and will, of course, involve very close collaboration with colleagues at GROS and NISRA. In the meantime, any researchers interested in exploring this as an option should contact their nearest user support team (contact 
details for these teams are provided at the end of this article). Any proposed projects will be considered by all three statistical offices on a case-by-case basis.

\section{Linking additional administrative data}

The richness of information in the ONS LS comes from matching census data with administrative data over time. These administrative data are currently limited to birth and death related data from the civil registration service, cancer data from the cancer registries and demographic data from the patient registration system.

The last Longitudinal Study review in 1998 recommended that the linkage of administrative data held by other government departments should be considered. The passing of the Statistics and Registration Service Act 2007, which came into effect in April 2008, provides the legal framework through which ONS can seek access to any data held by other government departments.

ONS and the Department for Work and Pensions (DWP) are currently working closely to make a case for linking unemployment related benefit data to the study. This is the first attempt to use the new legislation to extend the content of the ONS LS. It is intended that this will be the first of a number of new linkages that will enrich the data available through the study.

The aim of linking additional data is to extend the range of research topics that can be explored through the study. This will enhance the value of the study for existing users, as well as reach out to new users carrying out research in areas that the study cannot currently address. Users will be consulted to identify which additional data are most in demand. This will form part of a wider user review that will allow ONS to prioritise this alongside other development activity.

\section{Using the ONS LS}

ONS actively promotes use of the ONS LS while maintaining the confidentiality of the individuals in the sample. ONS LS records available for analysis are anonymised but the database contains individual-level data that have not been aggregated or disguised.

To ensure confidentiality, these microdata can only be accessed at ONS sites and can only be accessed from a secure area known as the Virtual Microdata Laboratory (VML). Support officers are available to help users extract and use the data.

For further information, or for an informal discussion about using the ONS LS, government and other non-academic users should contact the Microdata Analysis and User Support team at ONS.

Tel: 01633455844

email:maus@ons.gsi.gov.uk

Website: www.ons.gov.uk/about/who-we-are/our-services/longitudinal-study

Academic users should contact the CeLSIUS team at the London School of Hygiene and Tropical Medicine.

Tel: 02072994634

email: celsius@lshtm.ac.uk

Website: www.celsius.Ishtm.ac.uk 
For further information about the SLS, users should contact the Longitudinal Studies Centre Scotland at the University of St. Andrews.

Tel: 01334463992

email: Iscs@st-andrews.ac.uk

Website: www.Iscs.ac.uk/sls/

For further information about the NILS, users should contact the Northern Ireland Longitudinal Study - Research Support Unit (NILS-RSU) at Queen's University Belfast.

Tel: 02890828210 or 02890348199

email: nils-rsu@qub.ac.uk

Website: www.qub.ac.uk/research-centres/NILSResearchSupportUnit/

\section{References}

1 Portanti, M and Whitworth, S (2009) A comparison of the characteristics of childless women and mothers in the ONS Longitudinal Study, Population Trends 136, Summer 2009, pp 10-20. Available at: www.statistics.gov.uk/downloads/theme_population/Popular-Trends136.pdf

2 Blackwell, L, Lynch, K, Smith, J and Goldblatt, P (2003) Longitudinal Study 1971-2001: Completeness of Census Linkage, Series LS no. 10, September 2003. Available at: www.statistics.gov.uk/downloads/theme_population/LS_no10.pdf

3 Census 2001: Quality Report for England and Wales, 2005. Available at: www.statistics.gov.uk/StatBase/Product.asp?vlnk=14212

4 Young, $\mathrm{H}$ (2009) Technical Working Paper: Guide to parallel and combined analysis of the ONS LS, SLS and NILS, July 2009. Available at: www.celsius.Ishtm.ac.uk/UKLS/Guide\%20 to $\% 20$ parallel\%20and\%20combined $\% 20$ LS\%20analysis.doc 